\title{
Free recall as a function of test anxiety, concreteness, and instructions
}

\author{
JOHN H. MUELLER and THOMAS D. OVERCAST \\ University of Missouri, Columbia, Missouri 65201
}

\begin{abstract}
Subjects of high or low test anxiety learned a free recall list composed of either concrete or abstract nouns, under instructions to think of images, phrases, or with no special strategy. Anxiety had no significant effect on total recall or subjective organization. High-anxiety subjects seemed to utilize a strategy of recall from short-term memory, though they had smaller digit spans than low-anxiety subjects. There was also a tendency for high-anxiety subjects under certain mnemonic instructions to give greater output priority to previously unrecalled items than did low-anxiety subjects.
\end{abstract}

Recent research has shown that high-anxiety subjects do not perform as well as low-anxiety subjects on a free recall task (cf. Mueller, 1976). While high-anxiety subjects may recall as many items, their recall displays less organization, e. g., less clustering of categorically related words. This result can be interpreted in terms of a cue utilization deficit, such that high-anxiety subjects do not encode as broad a range of features as low-anxiety subjects. Thus, high-anxiety subjects are not as able to benefit from the presence of intralist relationships in organizing their recall.

An important question here is whether there is any particular type of feature that is less likely to be encoded by high-anxiety subjects, or whether their deficit involves most intralist relationships. What little evidence is available suggests that the deficit may be more apparent for the semantic properties of words. For example, there is some evidence to suggest that high arousal leads to a concentration on physical features rather than semantic features (Broadbent, 1971; Schwartz, 1975).

The present experiment examined whether imaginal processes were related in any way to reduced cue utilization under high anxiety. The rationale for examining item imagery derives from the dual-coding hypothesis (cf. Paivio, 1971). It is generally found that recall is better for concrete words than for abstract words. The dual-coding analysis assumes that concrete items may be processed through either an imaginal encoding system or a verbal-symbolic processing system, or both, while abstract items can be processed only through the latter. In view of the fact that high-anxiety subjects seem to encode more restrictively, one possibility is that they would not benefit from the alternative (redundant) encodings that are possible for the concrete items, i. e., the superiority of concrete items in recall would be limited to low-anxiety subjects. Furthermore,

Requests for reprints should be sent to John Mueller, Psychology Department, 210 McAlester Hall, University of Missouri, Columbia, Missouri 65201. since it is typically found that subjects told to form images perform better than uninstructed subjects, it seemed of interest to examine whether this benefit could reduce any deficit associated with high anxiety. Therefore, the nature of the study instructions was also varied in the present study.

\section{METHOD}

\section{Subjects and Design}

The subjects were 72 men and 72 women from introductory psychology classes, selected on the basis of test anxiety scores (Sarason, 1972). High-anxiety subjects all had scores of at least 19 (mean $=26.6)$, and low-anxiety subjects had scores below 15 $($ mean $=8.5)$. Six men and six women were assigned to each of the 12 groups created by the factorial combination of two levels of test anxiety (high, low), two types of lists (concrete, abstract), and three instructional conditions (images, phrases, controls).

\section{Materials}

The concrete list was composed of 20 high-imagery nouns selected from the Paivio, Yuille, and Madigan (1968) norms. All had rated imagery of at least 5.10 (mean $=6.15$ ), and were A or AA in Thorndike-Lorge frequency. The abstract list was composed of 20 low-imagery nouns (mean $=3.06$ ), A or AA in frequency, and this list was equal to the concrete list in terms of meaningfulness. Each list was arranged in six random orders for presentation.

\section{Procedure}

Each subject performed for six trials on one of the free recall lists. The items were presented visually at a 2 -sec rate. In addition to general free recall instructions that emphasized the option to recall in any order, some subjects received additional instructions to form images combining several words in a scene, or to form verbal phrases combining words. An illustrative example was given in each case, and it was suggested that three to five words per grouping might work best. An immediate 60 -sec written test followed the presentation of the last item on each trial.

After the sixth trial, subjects had a series of forward and backward digit-span tests (from the WAIS subtest) requiring about $4 \mathrm{~min}$. They then answered some questions concerning their general usage of imagery. Finally, subjects were given an unpaced final recall test, without further study. 
Table 1

Average Recall Performance by List Type, Mnemonic Instructions, and Test Anxiety

\begin{tabular}{|c|c|c|c|c|c|}
\hline \multirow[b]{2}{*}{ Group } & \multicolumn{4}{|c|}{ Trials 1-6 } & \multirow{2}{*}{$\begin{array}{c}\text { Delayed } \\
\text { Recall } \\
\text { Test }\end{array}$} \\
\hline & $\begin{array}{c}\text { Recall } \\
\text { per Trial }\end{array}$ & $\begin{array}{l}\text { ARC } \\
\text { Score }\end{array}$ & $\begin{array}{r}\text { RIP } \\
\text { Score }\end{array}$ & $\begin{array}{c}\text { STS } \\
\text { Recall }\end{array}$ & \\
\hline \multirow{2}{*}{\multicolumn{6}{|c|}{ Uninstructed }} \\
\hline & & & & & \\
\hline High Anxiety & 14.00 & .22 & .32 & 2.22 & 16.83 \\
\hline Low Anxiety & 14.24 & .17 & .21 & 1.86 & 16.92 \\
\hline \multicolumn{6}{|l|}{ Image Mnemonic } \\
\hline High Anxiety & 13.99 & .19 & .24 & 2.24 & 16.42 \\
\hline Low Anxiety & 14.78 & .16 & .08 & 2.16 & 18.00 \\
\hline \multicolumn{6}{|c|}{ Verbal Mnemonic } \\
\hline High Anxiety & 15.21 & .20 & .26 & 2.46 & 17.25 \\
\hline \multirow[t]{2}{*}{ Low Anxiety } & 15.38 & .21 & .33 & 1.92 & 17.75 \\
\hline & \multicolumn{4}{|c|}{ Abstract List } & \\
\hline \multicolumn{6}{|l|}{ Uninstructed } \\
\hline High Anxiety & 11.49 & .14 & .33 & 2.36 & 13.33 \\
\hline Low Anxiety & 11.17 & .10 & .28 & 2.16 & 13.58 \\
\hline \multicolumn{6}{|l|}{ Image Mnemonic } \\
\hline High Anxiety & 11.38 & .14 & .26 & 2.50 & 13.92 \\
\hline Low Anxiety & 11.63 & .18 & .18 & 2.30 & 13.58 \\
\hline \multicolumn{6}{|c|}{ Verbal Mnemonic } \\
\hline High Anxiety & 12.22 & .17 & .14 & 2.60 & 15.17 \\
\hline Low Anxiety & 12.35 & .17 & .29 & 2.52 & 15.75 \\
\hline
\end{tabular}

\section{RESULTS AND DISCUSSION ${ }^{1}$}

\section{Immediate Recall}

The primary results are summarized in Table 1 . In terms of immediate recall, there was no main effect of Anxiety, nor did anxiety interact with Type of List or Mnemonic [Fs $<1]$. There was the expected superiority of concrete items $[\mathrm{F}(1,132)=92.13, \mathrm{MSe}=19.63]$, but there was no List by Mnemonic interaction $[F<1]$. The Mnemonic main effect was significant $[F(2,132)=4.65$, MSe $=19.63$ ] but, instead of superiority for images, the verbal mnemonic proved to be best for both lists. Pooled over lists and trials, mean recall was 13.79 for the verbal strategy, 12.94 for the images strategy, and 12.72 for the control group.

Pellegrino's (1972) adjusted ratio of clustering (ARC) score was used as the measure of subjective organization. Table 1 presents the average score for intertrial repetitions of two words, using a lenient bidirectional scoring (statistical conclusions were the same for a unidirectional scoring). The maximum ARC score is 1.0 . The Anxiety main effect was not significant, and Anxiety did not interact with either List or Mnemonic [Fs $<1]$. The concrete list was somewhat more organized overall than the abstract list $[\mathrm{F}(1,132)=3.09, \mathrm{MSe}=.10, \mathrm{p}<.08]$, and the List by Trials interaction indicated that the concrete list was more organized early, but the abstract list improved to the same level over trials $[\mathrm{F}(5,660)=3.07$, MSe $=.05]$. There was no Mnemonic main effect, nor interaction of List with Mnemonic [Fs $<1]$.

Another feature of organization in recall is the extent to which subjects give priority in output to items not recalled on previous tests. The relative index of priority (RIP) score (Flores \& Brown, 1974) was computed to assess this component of recall over the first six trials. Positive values reflect early output for the "new" items, with a maximum of 1.0 . The only significant effect was an Anxiety by Mnemonic interaction $[\mathrm{F}(2,132)=3.15$, MSe $=.28]$. High-anxiety subjects utilized this strategy to a greater extent than low-anxiety subjects with the image mnemonic and with no mnemonic instructions, while low-anxiety subjects utilized it more with the verbal mnemonic. The interpretation of this interaction is unclear. There were no Anxiety, List, or Mnemonic main effects, and no Anxiety by List or List by Mnemonic interactions [Fs $<1]$.

It was also possible to examine recall from short-term memory, using the technique of Tulving and Colotla (1970). For this analysis, if fewer than seven input and/or output events separated the presentation of an item from its recall, it was scored as being recalled from the short-term store (STS). This component of recall was greater in general for high-anxiety subjects $[\mathrm{F}(1,132)=4.82, \mathrm{MSe}=1.14]$, but Anxiety did not interact with List or Mnemonic [Fs $<1]$. (An examination of probability of recall plotted as a function of input position did not reveal a more pronounced recency effect for high-anxiety subjects.) This recall component was more pronounced overall with the abstract list $[\mathrm{F}(1,132)=5.50, \mathrm{MSe}=1.14]$, but there was no Mnemonic main effect or List by Mnemonic interaction [Fs $<1.44]$.

\section{Digit Span}

The digit-span test, an alternative index of short-term memory, revealed inferior performance for the highanxiety subjects on both forward and backward tests [Fs $(1,32)=5.10$ and $2.95, \mathrm{MSe}=1.07$ and 0.94 , respectively]. For high- and low-anxiety subjects, mean forward spans were 7.15 and 7.54, and mean backward spans were 6.56 and 6.83 , respectively.

\section{Delayed Recall}

Recall on the delayed test was greater for the concrete list $[\mathrm{F}(1,132)=56.02, \mathrm{MSe}=5.68]$ and the verbal mnemonic remained superior to the imagery mnemonic and control group $[F(2,132)=3.97$, $\mathrm{MSe}=5.68]$, with no interaction of List by Mnemonic $[\mathrm{F}<1.38]$. The Anxiety main effect was not significant $[\mathrm{F}<1.26]$, nor did Anxiety interact with List or Mnemonic [Fs $<1]$.

In conclusion, the present results indicate very little effect on free recall due to differences in test anxiety. Total recall was not affected by anxiety for either concrete or abstract lists, nor did subjective organization seem to be related to anxiety level for either list. Since concrete words were recalled better as usual, and the concrete list was more organized, it seems possible to tentatively conclude that imaginal processes 
are not qualified by test anxiety. In other words, within the limits of the present manipulations, concreteness as an item attribute seems not to be a dimension involved in any cue utilization deficit.

\section{NOTE}

1. Effects described as significant involve $p<.05$ or better, unless noted otherwise.

\section{REFERENCES}

Broadbent, D. E. Decision and stress. London: Academic Press, 1971.

Flores, L. M., \& BRown, S. C. Comparison of output order in free recall. Behavior Research Methods \& Instrumentation, 1974, 6, 385-388.

MuelleR, J. H. Anxiety and cue utilization in human learning and memory. In M. Zuckerman \& C. D. Spielberger (Eds.), Emotions and anxiety: New concepts, methods and applications. Potomac, Md.: Erlbaum, 1976.
Paivio, A. Imagery and verbal processes. New York: Holt, Rinehart, and Winston, 1971.

Paivio, A., Yuille, J. C., \& Madigan, S. Concreteness, imagery, and meaningfulness values for 925 nouns. Journal of Experimental Psychology Monograph, 1968, 76 (1, Pt. 2).

Pellegrino, J. W. A FORTRAN IV program for analyzing higher order subjective organization units in free recall learning. Behavior Research Methods \& Instrumentation, 1972, 4, $215-217$

SARASON, I. G. Experimental approaches to test anxiety: Attention and uses of information. In C. D. Spielberger (Ed.), Anxiety: Current trends in theory and research. New York: Academic Press, 1972.

SCHWARTZ, S. Individual differences in cognition: Some relationships between personality and memory. Journal of Research in Personality, 1975, 9, 217-222.

Tulving, E., \& Colotla, V. A. Free recall of trilingual lists. Cognitive Psychology, 1970, 1, 86-98.

(Received for publication May 17, 1976.) 